\title{
STUDY ON THE EFFECT OF QUARRY DUST ON DEFLECTION CHARACTERISTICSOF COCONUT SHELL CONCRETE SLAB
}

\author{
S. Prakash Chandar* and K.Gunasekaran \\ Department of Civil Engineering, SRM IST, Kattankulathur-603203,Tamilnadu, India \\ *E-mail: ramprabu862@gmail.com
}

\begin{abstract}
Deflection characteristics of coconut shell concrete slabs using quarry dust as fine aggregate are studied and reported. Five concrete mixes A1, A2, A3, A4, and A5 were considered in different percentages of quarry dust in coconut shell concrete. Nine cubes were cast for each mix for 3, 7, and $28^{\text {th }}$ day (totally 45 cubes) test and found density and compressive strength of all mixes. Deflection characteristics of all the five slabs, one slab in each mix were tested at 28 days ago and the results are presented. When the percentage of quarry dust increases, density, and compressive strengths are also increased. Deflection of slabs is decreased as the percentage of quarry dust increases. It shows that the quarry dust exhibits less deflection compared to river sand used concrete. All the slabs satisfy the IS 456: 2000 code requirement of span to depth ratio. This study encourages to use the quarry dust in place of river sand in case of the recently developed coconut shell concrete also.
\end{abstract}

Keywords: Coconut shell; Quarry dust; Density; Strength; Deflection.

@ RASĀYAN. All rights reserved

\section{INTRODUCTION}

It is necessary to find the alternate materials for the conventional materials used in construction industries to make it economical and also to reduce the waste landfill. In India, huge of agricultural wastes and industrial wastes are dumped as landfill. Nowadays a lot of researchers have been involved in converting waste material as replacing materials in construction industries. This material replacement has two benefits one is, it reduces the material cost in construction and also reduces the waste to solve the environmental problems. Some of the examples are recycled aggregate ${ }^{1-2}$, marine algae ${ }^{3}$, RMC wastes $^{4}$, coconut shell ${ }^{5-6}$, etc. Coconut shell is such one of the agricultural waste and promised as one of the alternative materials for coarse aggregate and quarry dust is another waste for a replacement to river sand in concrete. Coconut shell concrete is one of the recently established concrete the coconut shell as coarse aggregate and the river sand as fine aggregate was used in that. Since the sources of river sand are depleting day by day everywhere and hence people are searching for an alternate material for the same. In view of this, already the combination of quarry dust in coconut shell concrete had been tried and published on the properties of mechanical, bond and durability properties ${ }^{7-8}$. Therefore, in continuation of these properties, a study on deflection characteristics of coconut shell concrete slab using quarry dust as fine aggregate is proposed in this study and presented.

\section{EXPERIMENTAL}

\section{Cement}

Binder(OPC) 53-grade cement as per IS12269:1987 ${ }^{9}$ specificationswere used in this study.

\section{Fine Aggregate}

River sand (RS) which is available from the nearby river was used as fine aggregate in the manufacturing of coconut shell and control concretes. The specific gravity of river sand was 2.65 and falls in the zone II types of fine aggregate as per IS 383:2016 ${ }^{10}$ - Specification for coarse and fine aggregates from natural sources for concrete.

Rasayan J. Chem., 12(3), 1038-1042(2019)

http://dx.doi.org/10.31788/RJC.2019.1235233

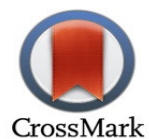


RASĀYAN J. Chem.

Vol. 12 | No. 3 |1038 - 1042| July - September | 2019

\section{Quarry Dust (QD)}

It is a by-product of crushing the stone, process which is used as an alternate material for river sand fine aggregates focussed in this study. The specific gravity of fine aggregate quarry dust was 2.64 and falls in the zoneIII type of fine aggregate as per IS $383: 2016^{10}$ - Specification for coarse and fine aggregates from natural sources for concrete.

\section{Coconut Shell (CS)}

Coconut shells were collected from markets and the collected raw materials of coconut shell were crushed to the size of maximum $12.5 \mathrm{~mm}$ in length using the crusher which is developed and installed in SRM Institute of Science and Technology, Chennai. The moisture content and water absorption properties of $\mathrm{CS}$ are more when compared to normal stone aggregate, therefore it was decided to use in the saturated surface dry (SSD) condition after $24 \mathrm{~h}$ soaking period before introduced into the concrete for coconut shell concrete (CSC) as proposed in the earlier studies. ${ }^{7-8}$

\section{Methodology}

In the experimental program slab size, $533 \times 838 \times 40 \mathrm{~mm}$ was selected based on the test setup available for testing deflection of the slab in the structural testing laboratory in SRM Institute of Science and Technology. Five mixes were used in which the mixes are designated as A1 (100\% river sand), A2 (75\% river sand and 25\% quarry dust), A3 (50\% river sand and 50\% quarry dust), A4 (25\% river sand and $75 \%$ quarry dust) and A5 (100\% quarry dust). For each mix, companion cubes of size $100 \times 100 \times 100 \mathrm{~mm}$ were used and test conducted for compressive strength as per IS 516:1959[11] at 3, 7 and 28 days. In all these mixes, cement content of $510 \mathrm{~kg} / \mathrm{m}^{3}$ was used as used in the previous studies ${ }^{7-8}$. Table 1 presents the mix types, $\%$ of river sand and quarry dust and the corresponding mix ratios used. Required molds were prepared using the plywood as per the size of the slab and cast the one slab for each mixes A1 to A5. After casting of slabs, all the slabs were covered with plastic sheets immediately to avoid the evaporation moisture from the top surfaces of the slabs. Passing $24 \mathrm{~h}$ time, slabs were removed from the molds and placed for curing. After 28 days of age, slabs were left for surface drying and applied whitewash before testing. Also, before testing, required markings were plotted on the specimen and then placed in the loading frame and provided simply supported on all the four edges of the slab. Before start doing the test, the alignment of the slab was tested and checked using the plumb bob and leveling for making concurrent of both slab center and loading from the center. At the center of the slab, steel ball was placed and plaster of Paris was applied to hold the steel ball in its position. Over the steel bar, hydraulic jack was placed and then proving ring was placed over the jack. This arrangement was made for the application of concentrated load at the center of the slab. Exactly below the steel ball, at the bottom of the slab, dial gauge was placed to measure the central deflection. Loads were gradually transferred to the slab and continued till the slab reaches its ultimate capacity. For every increment of loads, deflections were noted and the formation of cracks also checked. Figure- 2 shows the testing arrangement of a slab for deflection study.

Table-1: Mix Type and Ratios Used

\begin{tabular}{c|l|l}
\hline S. No. & \multicolumn{1}{|c}{ Coconut Shell Concrete } & \multicolumn{1}{c}{ Mix Ratio } \\
& & \multicolumn{1}{c}{ Cement: Sand: Quarry Dust: Coconut Shell: Water } \\
\hline A1 & 100\% River sand & $1: 1.47: 0.65: 0.42$ \\
\hline A2 & $75 \%$ River sand ,25\% quarry dust & $1: 1.10: 0.39: 0.65: 0.42$ \\
\hline A3 & $50 \%$ River sand ,50\% quarry dust & $1: 0.73: 0.79: 0.65: 0.42$ \\
\hline A4 & 25\% River sand ,75\% quarry dust & $1: 0.37: 1.18: 0.65: 0.42$ \\
\hline A5 & $100 \%$ Quarry dust & $1: 1.58: 0.65: 0.42$ \\
\hline
\end{tabular}

\section{Compressive Strength}

\section{RESULTS AND DISCUSSION}

For all the mixes A1 to A5, compressive strength was found at 3, 7 and 28 days as per IS 516: $1959^{11}$ and presented in Table-2. Figure-3 illustrates the graphical representations of the compressive strength of different mixes A1 to A5. 
RASĀYAN J. Chem.

Vol. 12 | No. 3 |1038 - 1042| July - September | 2019

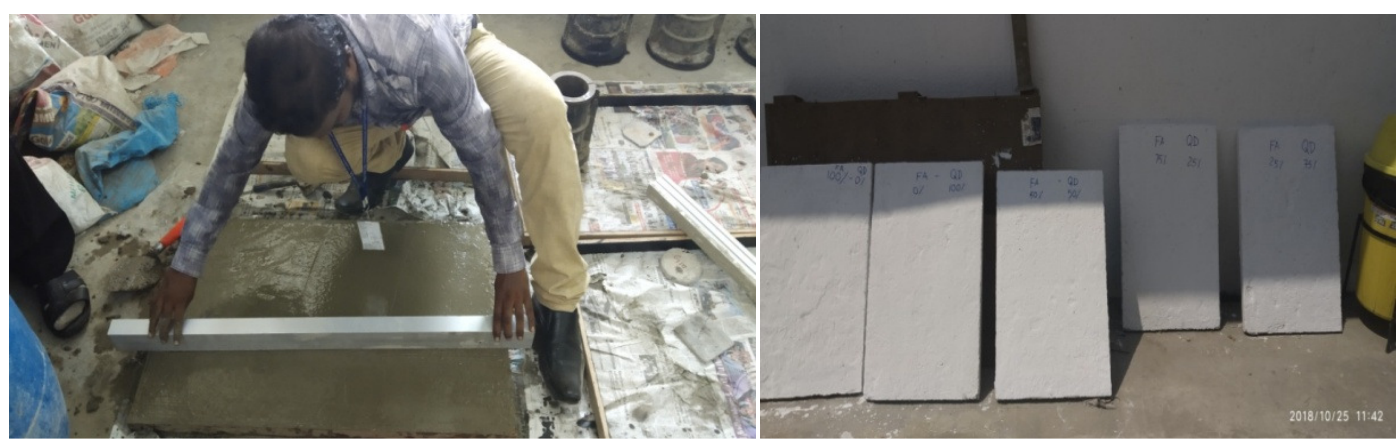

Fig.-1: (a)Slabs under casting, (b) Cast slabs before the test
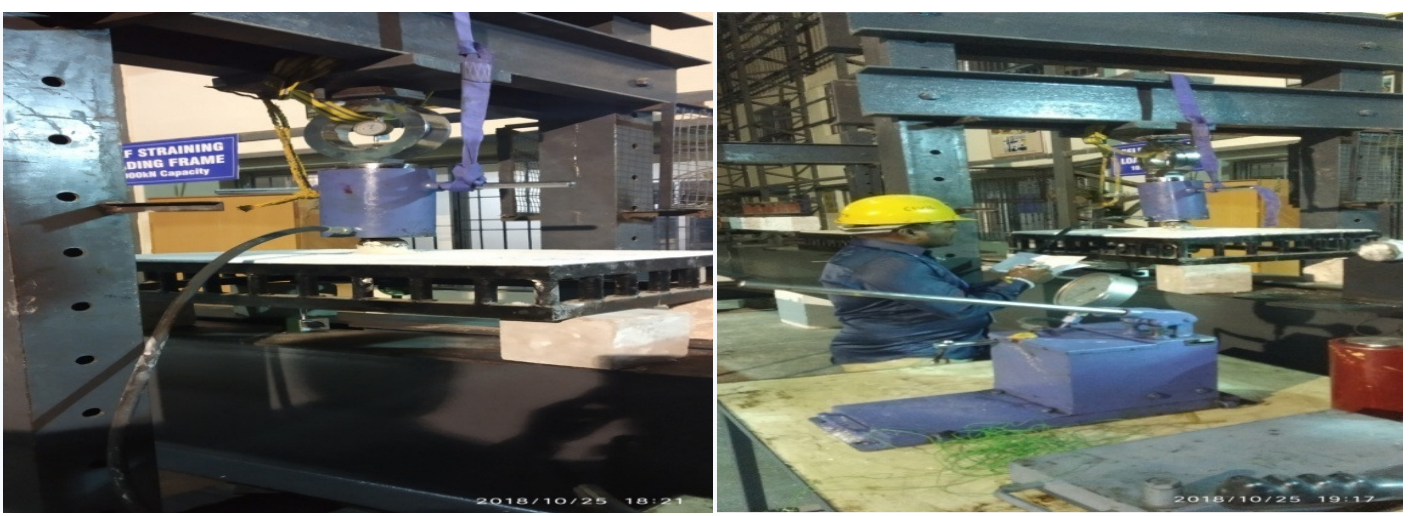

Fig.-2: Testing of a slab for Deflection Study

Table-2: Compression Strength Test Results

\begin{tabular}{c|l|c|c|c|c}
\hline Mix Type & Percentage of & Fresh Density $\left(\mathrm{kg} / \mathrm{m}^{3}\right)$ & \multicolumn{3}{|c}{ Compressive Strength $\left(\mathrm{N} / \mathrm{mm}^{2}\right)$} \\
\cline { 4 - 6 } & & & $3^{\text {rd }}$ day & $7^{\text {th }}$ day & $28^{\text {th }}$ day \\
\hline A1 & $100 \%$ RS & 2040 & 16.49 & 19.78 & 26.45 \\
\hline A2 & $75 \%$ RS ,25\% QD & 2070 & 16.65 & 20.40 & 27.10 \\
\hline A3 & $50 \%$ RS ,50\% QD & 2085 & 16.78 & 20.55 & 27.94 \\
\hline A4 & $25 \%$ RS ,75\% QD & 2115 & 16.82 & 20.62 & 28.15 \\
\hline A5 & $100 \%$ QD & 2150 & 17.18 & 20.80 & 28.42 \\
\hline
\end{tabular}

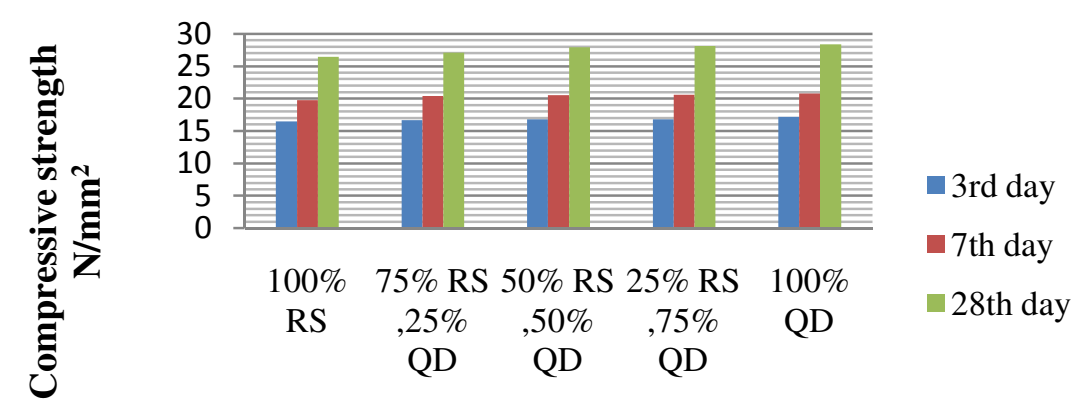

Different \% used for RS and QD

Fig.-3: Compressive Strength Vs Different Mixes 


\section{Deflection Characteristic on Slabs}

Table-3 presented the results observed from the deflection tests on all the five slabs. From the results of deflection tests on each slab, the load versus deflection graph is plotted and shown in Fig.-4.

Table-3: Deflection on a Slab at the $28^{\text {th }}$ Day of Different Mixes

\begin{tabular}{c|c|c|c|c|c}
\hline \multirow{2}{*}{ Load in kg } & \multicolumn{5}{|c}{ Deflection $(\mathrm{mm})$} \\
\cline { 2 - 6 } & $\mathrm{A} 1$ & $\mathrm{~A} 2$ & $\mathrm{~A} 3$ & $\mathrm{~A} 4$ & $\mathrm{~A} 5$ \\
\hline 40 & 0.00 & 0.00 & 0.00 & 0.00 & 0.00 \\
\hline 80 & 0.17 & 0.16 & 0.15 & 0.15 & 0.15 \\
\hline 120 & 0.47 & 0.44 & 0.43 & 0.42 & 0.42 \\
\hline 160 & 0.97 & 0.90 & 0.87 & 0.86 & 0.85 \\
\hline 200 & 1.37 & 1.27 & 1.23 & 1.22 & 1.21 \\
\hline 240 & 1.60 & 1.54 & 1.44 & 1.43 & 1.41 \\
\hline 280 & 2.14 & 2.04 & 1.98 & 1.96 & 1.84 \\
\hline 320 & 2.69 & 2.43 & 2.36 & 2.33 & 2.21 \\
\hline 360 & -- & 2.64 & 2.56 & 2.54 & 2.51 \\
\hline
\end{tabular}

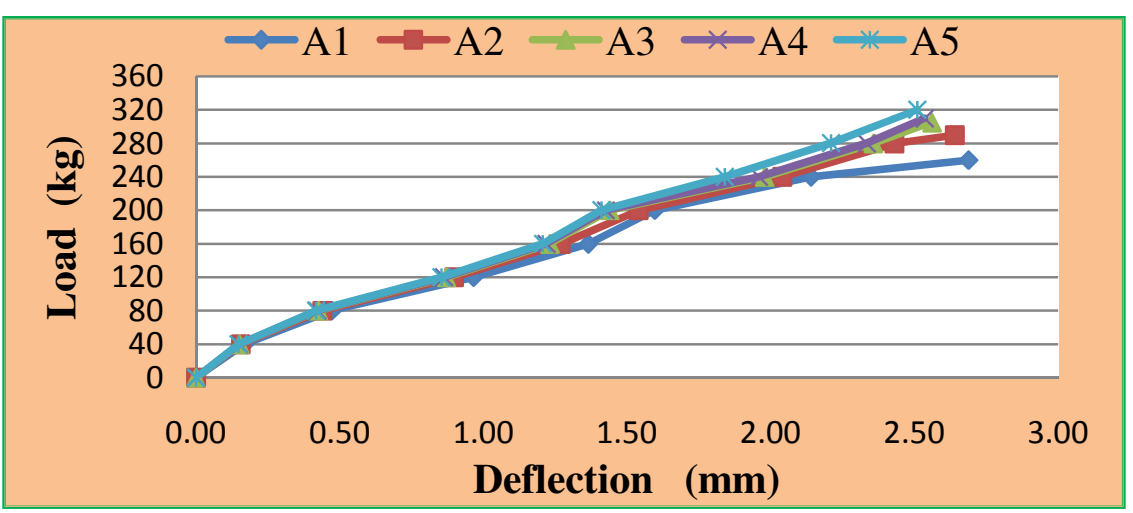

Fig.-4: Load Vs Deflection of A1 to A5 mixes

From the above results presented both in Table-3 and Fig.- 4, it can be seen that the central deflections of slab decrease as the percentage of quarry dust increase in the presence of fine aggregate. It shows that quarry dust exhibits less deflection compared to river sand. Figure-4 clearly shows that the deflection curves trends are very similar to all the mixes (A1 to A5 mixes) almost from the starting to till the end except A1 mix (100\% river sand used slab). This show that the use of quarry dust will do its best similar to river sand. However, it was found that at the ultimate stage, A1 mix slab where $100 \%$ river sand used slab delayed in breaking comparatively but it is not so in case of A5 mix slab where $100 \%$ quarry dust used slab. But this slight difference is not that much significant since only one slab in each case, that too without reinforcement. Therefore, to find out this phenomenon further studies are to be done before concluding any remarks on this.

When considering the span (l) to depth (d) ratio of the tested slabs (i.e) (533/40) $13.33 \mathrm{~mm}$ is maximum permissible value, which is less than the 35 for two way slab as per IS 456: 2000. In this study, the maximum experimental deflection for various mixes A1 to A5 varies in the range of 2.51 to $2.69 \mathrm{~mm}$ which is less than the permissible limit of $13.33 \mathrm{~mm}$.

\section{CONCLUSION}

- Since the specific gravity of the quarry dust is comparatively high compared to river sand, the density of mixes increases as the percentage of quarry dust increases in place of river sand, in turn, compressive strength also. 
- Deflection results show that if the presence of quarry dust increases, the central deflection of the slab decreases. It shows the quarry dust exhibit less deflection compared to river sand used concrete.

- At the ultimate stage, $100 \%$ river sand used slab delayed in breaking comparatively but it is not so in case of where $100 \%$ quarry dust used slab.

- All the slabs satisfy the IS 456: 2000 code requirement of span to depth ratio.

- It should, however, further works are to be carried out before it can be used along with reinforcement.

\section{REFERENCE}

1. S. Prakash Chandar, K. Gunasekaran, N.Sai Sandeep et al., Rasayan Journal of Chemistry, 10(2),528 (2017), DOI: 10.7324/RJC.2017.1021636.

2. S. Prakash Chandar, K.Gunasekaran, K. Prasanth et al., Rasayan Journal of Chemistry, 11(2), 702(2018), DOI: 10.31788/RJC.2018.1123003.

3. R. Ramasubramani, K. S. Sathyanarayanan, et al., Rasayan Journal of Chemistry, 9, 706(2016).

4. L. Krishnaraj, R.Suba Lakshmi, P. T. Ravichandran, Rasayan Journal of Chemistry, 10(2), 592(2017), DOI: 10.7324/RJC.2017.1021670.

5. K. Gunasekaran, P. S. Kumar, M. Lakshmipathy, International Journal of Construction and Building Materials, 25, 92(2011), DOI: 10.1016/j.conbuildmat.2010.06.053.

6. K. Gunasekaran, R. Ramasubramani, R.Annadurai, S.PrakashChandar, International journal of Materials and Design, 57, 374(2014), DOI: 10.1016/j.matdes.2013.12.058.

7. K. Gunasekaran, S. Praksah Chandar, R. Annadurai and K.S. Satyanarayanan., European Journal of Environmental and Civil Engineering, 21, 629 (2016), DOI: 10.1080/19648189.2016.1144540.

8. S. Prakash Chandar, K. Gunasekaran, K. S. Satyanarayanan\& R. Annadurai, European Journal of Environmental and Civil Engineering, DOI: 10.1080/19648189.2017.1418435.

9. IS 12269:1987-Ordinary Portland cement 53grade

10. IS 383: 2016-Specification for coarse and fine aggregates from natural sources for concrete

11. IS 516:1959- Methods of tests for strength of concrete

[RJC-5233/2019] 